\title{
O bloco do saber do conjunto dos inteiros relativos The know pack of the relative whole of integers
}

\author{
KLEBER RAMOS GONÇALVES ${ }^{1}$ \\ MARILENA BITTAR ${ }^{2}$
}

\section{Resumo}

Nesse artigo apresentamos um esboço de algumas reflexões advindas da nossa pesquisa acerca do conjunto dos números inteiros relativos. Os resultados que obtivemos nos deixaram alguns desconfortos, que nos movimentaram e nos proporcionaram que refletíssemos acerca das dificuldades que encontramos em nossos processos de análises. Nossa dificuldade se deu quando modelamos as propostas de ensino contidas em um livro didático. Do nosso referencial teórico e metodológico, dentre as ferramentas que mobilizamos, destacamos o bloco do saber. Esse bloco permite justificar as técnicas utilizadas para a resolução das tarefas propostas, e será essa parte da modelagem que nos propomos a estudar e entender, justamente pela nossa dificuldade em modelar $e$ descrever esses elementos de uma praxeologia. Nossa escrita perpassará alguns outros aspectos dos processos de ensino dos números inteiros relativos que se mostraram importantes para os estudos dessas justificativas para as técnicas mobilizadas.

Palavras-chave: Bloco do saber. Modelos concretos. Números inteiros relativos. Teoria antropológica do didático.

\section{Resumen}

En este artículo presentamos un esbozo de algunas reflexiones provenientes de nuestra investigación acerca del conjunto de los números enteros relativos. Los resultados que obtuvimos nos dejaron algunas molestias, que nos movieron y nos proporcionaron que reflexionamos acerca de las dificultades que encontramos en nuestros procesos de análisis. Nuestra dificultad se dio en el momento en que modelamos las propuestas de enseñanza contenidas en un libro didáctico. De nuestro referencial teórico y metodológico, entre las herramientas que movilizamos, destacamos el bloque del saber. Este bloque permite justificar las técnicas utilizadas para la resolución de las tareas propuestas, y será esa parte del modelado que nos proponemos a estudiar y entender, justamente por nuestra dificultad en modelar y describir esos elementos de una praxeología. Nuestra escritura atravesará algunos otros aspectos de los procesos de enseñanza de los números enteros relativos que se mostraron importantes para los estudios de esas justificaciones para las técnicas movilizadas.

Palabras clave: Bloque del saber. Modelos concretos. Números enteros relativos. Teoría antropológica del didáctico.

\footnotetext{
${ }^{1}$ Secretaria Municipal de Educação de Campo Grande/MS, Brasil, kleberemic@ gmail.com

${ }^{2}$ Universidade Federal de Mato Grosso do Sul, Brasil, marilenabittar@gmail.com
} 


\title{
Résumé
}

Dans cet article, nous présentons un aperçu de quelques réflexions de notre recherche sur l'ensemble des entiers relatifs. Les résultats que nous avons obtenus nous ont laissé des désagréments qui nous ont émus et nous ont donné l'occasion de réfléchir sur les difficultés que nous rencontrons dans nos processus d'analyse. Notre difficulté s'est produite au moment où nous avons modélisé les propositions d'enseignement contenues dans un manuel. À partir de notre cadre théorique et méthodologique, parmi les outils que nous mobilisons, nous mettons en évidence le bloc de connaissances. Ce bloc permet de justifier les techniques utilisées pour résoudre les tâches proposées, et ce sera cette partie de la modélisation que nous nous proposons d'étudier et de comprendre, précisément à cause de notre difficulté à modéliser et décrire ces éléments d'une praxéologie. Notre écriture passera en revue d'autres aspects des processus d'enseignement des nombres entiers relatifs qui se sont avérés importants pour l'étude de ces justifications pour les techniques mobilisées.

Mots-clés : Bloc de savoir. Modèles concrets. Les entiers relatifs. Théorie anthropologique de la didactique.

\begin{abstract}
In this paper we present an outline of some reflections from our research on the set of relative integers. The results we obtained left us with some discomforts that moved us and gave us the opportunity to reflect on the difficulties we find in our analysis processes. Our difficulty occurred now when we modeled the teaching proposals contained in a textbook. From our theoretical and methodological framework, among the tools we mobilize, we highlight the knowledge block. This block allows to justify the techniques used to solve the proposed tasks, and it will be this part of the modeling that we propose to study and understand, precisely because of our difficulty in modeling and describing these elements of a praxeology. Our writing will per pass some other aspects of the teaching processes of the relative integers that have proved important for the study of these justifications for the mobilized techniques.
\end{abstract}

Keywords: Block of knowledge. Concrete models. Relative integers. Anthropological theory of didactics. 


\section{Introdução}

A Teoria Antropológica do Didático (CHEVALLARD, 1999) visa estudar as atividades humanas, em particular as matemáticas, investigando o comportamento dos saberes que habitam as instituições. Essa investigação trata das formas que esses saberes são produzidos e disseminados nas instituições de ensino. Para Chevallard (1996, p. 133) "qualquer instituição é, em certa medida, uma instituição didática", dessa forma, "como podemos [...] modelar, a realização da intenção didática presente numa dada instituição I?" (Ibid., 1996, p. 133, grifo nosso).

Essa pergunta pode ter diversas soluções, mas com certeza, essas respostas se darão em um sistema didático ${ }^{3}$. Esse sistema é formado por vários sujeitos da instituição de ensino, que assumem os papéis de professor e aluno, e esses sujeitos estarão envolvidos em processos de ensino e de aprendizagem de um dado objeto de estudo. A Teoria Antropológica do Didático nos oferece como ferramenta para modelar as atividades matemáticas de estudo uma organização praxeológica. Essa organização é formada por tipos de tarefas, técnicas, tecnologias e teorias, representados pelo quarteto praxeológico $[\mathrm{T}, \tau, \theta, \Theta]$. Este quarteto pode ser dividido em dois blocos: o bloco do saber/fazer $[\mathrm{T}, \tau]$ e o bloco do saber $[\theta, \Theta]$.

Resumidamente, a TAD passou por alguns movimentos evolutivos que acarretaram em novos avanços dessa teoria. Esses movimentos perpassaram os processos de transposição didática; os estudos da ecologia do saber; as atividades matemáticas dadas por meio das organizações praxeológicas e; os processos dos percursos de estudo e pesquisa, vinculados aos modelos epistemológicos de referência.

Em nossa pesquisa de mestrado, para estudarmos alguns aspectos da transposição didática da matemática formal para a matemática escolar utilizamos os modelos de organização praxeológica, com o objetivo de compreender os distanciamentos e aproximações entre o saber presente no nível do saber acadêmico e as propostas de ensino das operações de adição e subtração do conjunto dos inteiros relativos (GONÇALVES, 2016). Para a investigação do saber acadêmico realizamos um estudo da construção axiomática do conjunto dos números inteiros relativos e para o saber a ser ensinado analisamos um livro

\footnotetext{
${ }^{3}$ Para que um Sistema Didático, segundo Chevallard (1996, p. 134), possa continuar existindo é necessário que ele atenda a "uma série de condições 'ecológicas' para que [...], não apenas exista, mas continue a existir: para que ele possa funcionar” (Ibid., p.134 e 135, grifo do autor).
} 
didático destinado ao $7^{\circ}$ ano do ensino fundamental, que é o momento em que este conteúdo é apresentado aos estudantes.

Os resultados que obtivemos com a nossa pesquisa deixaram algumas inquietações e neste texto queremos refletir sobre a dificuldade que encontramos para as análises do bloco do saber, responsável pela justificativa das técnicas utilizadas para a resolução das tarefas propostas. Na busca por outros pesquisadores que também poderiam ter tido dificuldades semelhantes as nossas, lemos algumas pesquisas produzidas em nosso grupo de estudos, o DDMat ${ }^{4}$. Identificamos nessas leituras, por exemplo, análises que não identificaram “uma preocupação explícita por parte dos autores em justificar o uso da fórmula do cálculo de uma determinada área. Na maioria das resoluções analisadas o cálculo da área recai apenas na aplicação da fórmula” (FREITAS, 2015, p. 92). Ainda, para justificar a ausência desse bloco, percebemos que alguns pesquisadores organizaram as justificativas, não em discurso tecnológico e nem em discurso teórico e, sim, em um único bloco, como discurso tecnológico-teórico. Essa organização auxiliou o pesquisador em suas dificuldades para descrever o bloco do saber.

Este incômodo foi um dos fatores que nos motivaram a seguir no campo das pesquisas. Para o doutorado em curso do primeiro autor deste artigo, nos propomos a estudar e entender com mais aprofundamento esse bloco, buscando pelos motivos que podem causar essas dificuldades. Sendo assim, especificamente, neste artigo, trataremos do bloco do saber dos números inteiros relativos. Além das motivações inicias, nos embasaremos em outros aspectos gerados no decorrer das disciplinas cursadas no primeiro ano do curso de doutorado, fruto de reflexões e análises que realizamos acerca das dificuldades em descrever o bloco do saber.

\section{Motivações para o estudo do bloco tecnológico/teórico}

Nosso objetivo inicial, no mestrado, era modelar propostas de ensino sobre números inteiros relativos em livros didáticos. Estávamos incluídos em um projeto maior que tratava da análise desse material ${ }^{5}$. Em uma das etapas das análises surgiu a necessidade

\footnotetext{
${ }^{4}$ O Grupo de Estudos em Didática da Matemática - DDMat, vinculado ao Programa de Pós-graduação em Educação Matemática - PPGEduMat/UFMS, tem como principal objetivo discutir teorias da Didática da Matemática - conhecida como Didática Francesa - bem como desenvolver atividades de pesquisa e extensão. Para mais informações acessar o site: http://grupoddmat.pro.br/.

5 "Chaachoua e Comiti (2010) evidenciam o aporte da análise de livros didáticos para apreender (e compreender) relações institucionais de um objeto em uma determinada organização matemática. Esses autores discutem a análise de livros didáticos à luz da $\mathrm{TAD}$, propondo alguns elementos para a
} 
de entendermos um pouco mais profundamente as estruturas algébricas, essa parte mais formal da matemática acadêmica que fundamenta teoricamente o conjunto dos números inteiros relativos. Tal necessidade se deu diante de todas as justificativas que encontrávamos para a parte introdutória das propostas de ensino, que não pareciam estar vinculadas aos conceitos matemáticos que embasam esse conjunto numérico.

Essas justificativas estavam pautadas em modelos concretos, modelos baseados em situações cotidianas, nas quais se buscavam alguns aspectos que podiam ser comparados com as propriedades dos inteiros relativos,

Vejamos um exemplo na figura a seguir:

Figura 1 - Justificativas pautadas em modelos concretos.

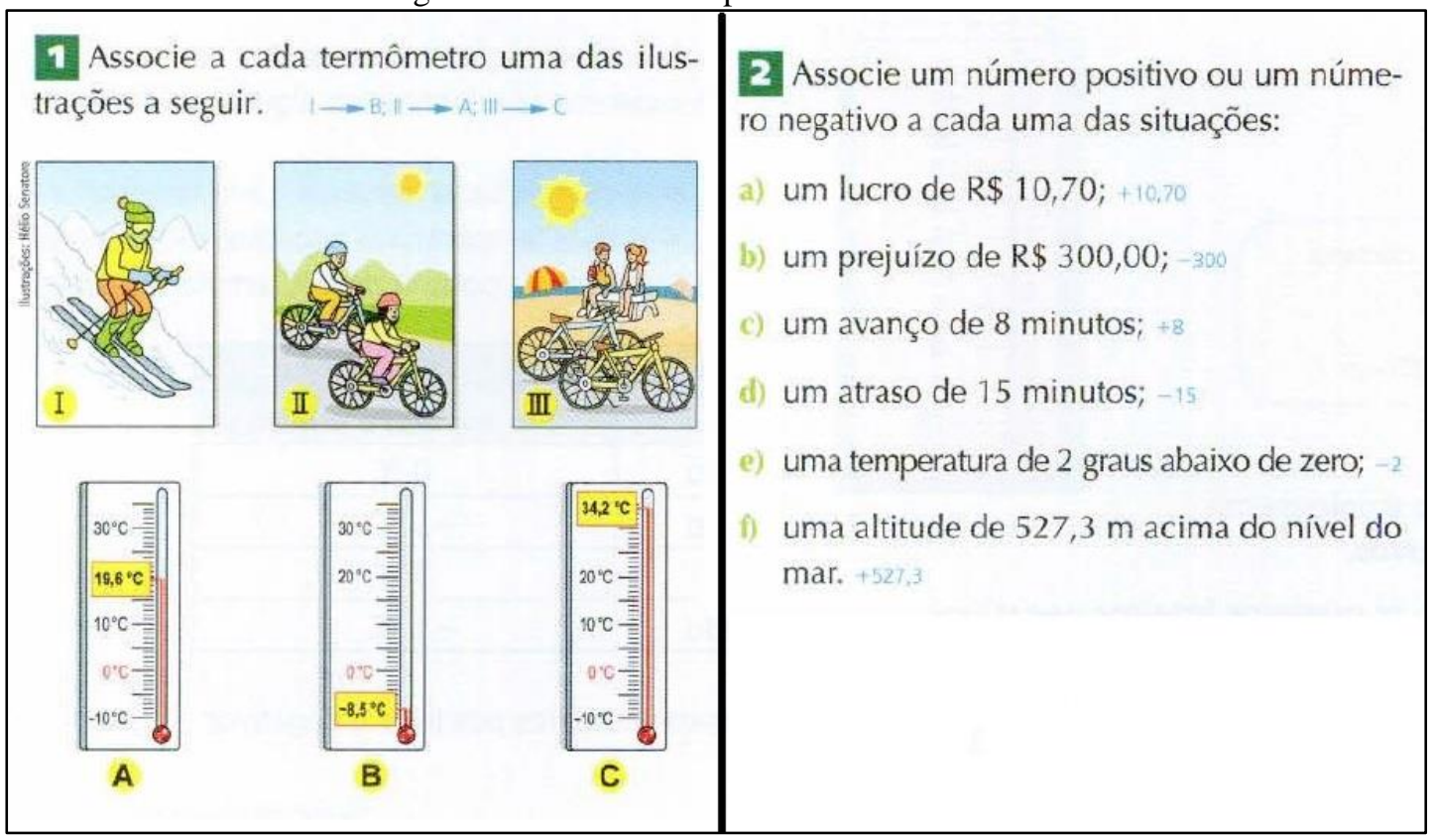

Fonte adaptada: Andrini e Vasconcellos, 2012, p. 57.

$\mathrm{Na}$ atividade à esquerda, pede para se associar figuras de termômetros com figuras de alguns ambientes cujas temperaturas são conhecidas: praia em um dia ensolarado, $34,2^{\circ} \mathrm{C}$; uma pessoa esquiando em uma montanha com picos congelados, $-8,5^{\circ} \mathrm{C}$; andando de bicicleta no parque pela manhã, $19,6^{\circ} \mathrm{C}$. E, na atividade à direita, pede-se para associar números positivos e negativos com determinadas situações: lucro de dez reais e setenta centavos, +10,70; avanço de 8 minutos, + 8; uma altitude de 527,3 m acima do nível do mar, + 527,3; entre outras.

caracterização desse material: o momento de edição (publicação); a representatividade da obra; a estrutura do livro; análise ecológica; e, por fim, a análise praxeológica” (BITTAR, 2017, p. 366). 
Ressaltamos que não esperávamos encontrar conceitos da matemática formal no livro analisado - Praticando Matemática, $7^{\circ}$ ano, cujos autores são Álvaro Andrini e Maria José Vasconcellos -, haja vista o nível de desenvolvimento cognitivo dos alunos a que se destinam. Queríamos compreender o que levou esses autores a realizarem essas escolhas metodológicas. Investigar o fato de que o que aparece para justificar as técnicas são adaptações, criações didáticas inventadas/criadas com intuito de se ensinar conceitos que estão prescritos no currículo de um determinado ano de escolaridade, e, que muitas das suas justificativas não possuem condições ecológicas de habitar esse ano de escolaridade. Essas escolhas estão ligadas às metodologias de ensino mobilizadas nas propostas de ensino. E, por meio da realização da construção axiomática dos inteiros articulada com a modelagem das praxeologias das propostas encontradas no livro didático, nos proporcionaram observar e relacionar supostos motivos que indicaram os processos transpositivos que esses conceitos sofreram desde o saber acadêmico até a sua estruturação no livro.

\section{Modelos concretos para o ensino dos números inteiros relativos}

A preocupação com o ensino do conjunto dos inteiros relativos surgiu da experiência como professor do ensino fundamental. Nesse período as dificuldades que os alunos estavam apresentando para compreender esse conceito eram muito grandes. A sequência didática posta em prática era fundamentada na Organização Didática encontrada nos livros didáticos. Alguns estudos ${ }^{6}$, ainda que empíricos, apontavam que já na parte introdutória apareceria a primeira grande dificuldade. $\mathrm{O}$ fato de os alunos estarem presos a algumas "regras" do conjunto dos números naturais, indicavam que eles não entenderiam algumas propriedades dos inteiros relativos. Por exemplo, em uma atividade que exigisse a comparação entre dois inteiros negativos, -5 e -1 , por mais que fosse explicado para eles, continuavam a usar a mesma técnica que comparavam dois naturais, ou seja, como 5 é maior do que 1, então, -5 é maior do que $\quad-1$. O trabalho que realizamos no mestrado nos ajudou a compreender que alguns dos erros metodológicos eram frutos da Organização Didática vigente em alguns livros didáticos.

\footnotetext{
${ }^{6}$ Algumas informações não são derivadas de ambos os autores desse artigo. Nesse caso, os estudos foram frutos da investigação da própria prática, realizada por um dos autores no decorrer de suas aulas. Mas, os resultados são empíricos, pois não foram mobilizados conhecimentos teóricos e, sim, conhecimentos adquiridos no decorrer de sua vida como professor.
} 
De acordo com Borba (2009, p. 59), “o professor se defronta com muitos questionamentos a respeito do desenvolvimento de conceitos por parte de seus alunos. [...] Como posso me certificar de que meus alunos estão compreendendo os conceitos trabalhados? Quais aspectos devo avaliar?" Essa autora ainda questiona além dos aspectos sobre conceitos, os modos que se deve trabalha-los de "forma a oferecer aos [...] alunos um contato amplo com os mesmos" (ibid., p.59). Como sugestão de respostas a essas perguntas, Borba (2009) afirma que é necessário conhecer como os conceitos são constituídos e também o seu desenvolvimento, dessa forma, os professores terão a oportunidade de ter um bom fundamento em seus processos avaliativos do desenvolvimento de seus planos de ensino. Nesse sentido, o estudo do bloco do saber, torna-se fundamental, pois não podemos conhecer o conceito sem olhar para as suas justificativas, a não ser que, seja para simplesmente reproduzir regras ou alguma metodologia de ensino.

As Organizações Matemáticas e as Organizações Didáticas identificadas no livro didático mobilizado na pesquisa de mestrado, principalmente, para a parte introdutória dos números inteiros relativos não apresentaram de forma clara as justificativas matemáticas. Essa forma de apresentação não dá suporte para os professores conhecerem como os conceitos são constituídos e como são desenvolvidos, e também não oferece condições para os alunos vivenciarem situações com a variação não somente dos contextos, mas das dimensões que constituem esse saber. Dentro de um mesmo contexto há possibilidade de ter problemas de diferentes significados (medidas ou relações), problemas diretos ${ }^{7}$ ou inversos e, problemas com diferentes representações simbólicas (oral, escrita ou por meio de materiais concretos) (BORBA, 2009), que podem propiciar aos alunos uma vivência com diversificados significados dos conceitos dos números inteiros relativos.

Borba (2009, p. 69) afirma que “a compreensão de um conceito é influenciada pelos significados dados, pelas propriedades sendo tratadas e pelas representações simbólicas sendo utilizadas ao se raciocinar sobre o conceito em questão". O processo descrito perpassa as justificativas dadas para as formas de resolução de uma tarefa. Por exemplo, para a tarefa somar dois inteiros relativos $(-2)+(-3)$, em alguns livros didáticos encontramos como uma técnica de resolução a mobilização, em forma de alusão, aos

\footnotetext{
${ }^{7}$ Há possibilidade de uma mesma operação ser representada por contextos distintos, vejamos: Contexto de temperatura, "Me ajude com uma curiosidade, respondendo em quantos graus a temperatura aumentou, para passar de $18^{\circ}$ a $30^{\circ}$ do início ao final de um dia?" Contexto monetário, "Pela manhã ganhei R $\$ 18,00$ para comprar minhas passagens de ônibus da semana. Mas, percebi que gastaria $R \$ 30,00$ com as passagens. E, agora? Quanto será que terei que completar para obter o valor necessário?” Em ambos casos a operação que resolve os problemas é $\quad 30-18$.
} 
andares de um prédio. A resolução procederia assim: estou no segundo andar do subsolo $(-2)$ e tenho que descer mais três andares, ou seja, do -2 desço até $o-5$, pois $(-2)+(-$ $3)=-5$. A mobilização dessa ideia (andares de prédios) também é usada para se determinar se uma quantidade é positiva ou negativa, ou seja, todos os andares acima do térreo representam valores positivos, os abaixo do térreo, os valores negativos e o térreo é a representação do zero. Percebe-se assim, que a justificativa para essa técnica está associada à comparação do comportamento de algumas características desse modelo concreto com algumas das propriedades dos inteiros relativos.

Esse modelo pode ser considerado como concreto e de deslocamento ${ }^{8}$ e, nele se observa uma inversão de procedimentos. Para os estudos de modelagem matemática, percebe-se que são as situações cotidianas que são modeladas, cria-se novos modelos matemáticos para representa-la ou algum modelo pré-determinado é adaptado para a situação estudada. E para os números inteiros relativos, particularmente, para o modelo que apresentamos, mas não apenas esse, pois existem tantos outros, mobiliza-se uma situação cotidiana para se "modelar" um conceito matemático. Não encontramos escrito, mas subentende-se que algumas características dessa situação podem ser associadas a algumas propriedades ou aspectos dos inteiros relativos. No caso dos andares dos prédios, a ideia é a da reta numérica e suas características de deslocamentos. Nessa forma de ensino, o fato de o aluno conseguir compreender e utilizar as regras dadas no modelo, pode ser garantia de que eles compreenderam os conceitos que se pretendia estudar por meio do modelo. $\mathrm{O}$ problema se configura em não ter institucionalização desses conceitos, uma formalização das propriedades, dos significados e de suas representações. O ensino está focado no trabalho com a técnica, sem que haja compreensão, lembrando que essa situação pode acontecer quando as justificativas não foram estudadas.

É preciso considerar o fato de que esses modelos concretos não podem ser associados a todas as características das estruturas algébricas por detrás dos inteiros (CID, 2010).

\footnotetext{
Os modelos concretos não refletem a estrutura de corpo comutativo totalmente ordenado que caracteriza os números reais (ou, mais particularmente, o anel comutativo totalmente ordenado e com unidade dos números inteiros), mas o espaço vetorial unidimensional, no caso de modelos de neutralização, ou espaço unidimensional afim, no caso de modelos de deslocamento (CID, 2010, p. 578).
}

\footnotetext{
8 Modelo de deslocamento, os números inteiros expressam deslocamentos ou posições; os sinais predicativos, a direção do deslocamento ou a situação da posição para um ou outro lado da posição de origem; os sinais operatórios binários, a composição de deslocamentos ou aplicação de um deslocamento a uma posição para obter outra posição; e o unitário, manutenção ou mudança de direção de deslocamento (CID, 2010, p.577, tradução nossa).
} 
Dessa forma, percebe-se que a utilização desses modelos se dá por algumas poucas características, pois quando levamos em conta um anel comutativo ordenado, considerase um conjunto munido de duas operações, em que várias são as propriedades ${ }^{9}$ que devem ser validadas. Cid (2010) traz uma aproximação com espaços vetoriais e espaços afins para os modelos de deslocamento e de neutralização, "embora todos eles sejam equivalentes, para mostrar a estrutura do espaço vetorial de Números Reais não são exatamente a melhor maneira de introduzir a ordem total compatível com as operações de um corpo totalmente ordenado" (ibid., p. 578).

A seguir trataremos de um exemplo do bloco do saber que identificamos no livro didático analisado, que retrata a mobilização de um modelo concreto para o ensino dos inteiros relativos.

\section{O bloco do saber dos números inteiros relativos}

Para a discussão do bloco do saber dos inteiros relativos vamos nos basear em um exemplo retirado das análises realizadas para a escrita da nossa dissertação. Mostraremos as principais justificativas para o bloco do saber retratada pelos autores para a realização da tarefa em que os alunos devem determinar entre dois inteiros relativos qual é o maior. Essa tarefa será uma das justificativas para as operações com números inteiros. As propriedades e procedimentos que se consegue identificar como justificativas para as tarefas que envolvem as operações são fundamentadas na parte considerada como introdutória ${ }^{10}$ pelos autores desse livro, que fundamentalmente, se baseiam em modelos da realidade.

A mobilização de modelos concretos é legitimado pelos autores da seguinte maneira:

O primeiro passo é criar um ambiente de aprendizado que permita dar significado ao que se aprende, aproximando a Matemática do dia a dia do aluno. Nesse sentido, a contextualização de conteúdos exerce papel de destaque e deve ser explorada. Na obra, a contextualização de conteúdos está presente, mas de forma criteriosa, cuidando para não levar à banalização e à perda de consistência. (ANDRINI, VASCONCELLOS, 2012, p. 5).

\footnotetext{
${ }^{9}$ Propriedades: associativa da soma e da multiplicação, comutativa da soma, existência do elemento neutro, existência do inverso aditivo e distributiva do produto em relação à soma. Quando também for válida a propriedade existência da unidade em $\mathbb{Z}$, ele será chamado de anel com unidade 1; se a propriedade comutativa da multiplicação também for verificada, então ele será chamado de anel comutativo.

${ }^{10}$ Nessa parte introdutória os autores iniciam o ensino dos números inteiros relativos expondo a dificuldade de se resolver a seguinte operação " 3 - 5". Eles mobilizam uma figura que representa profundidades abaixo do nível do mar e um gráfico com lucros e prejuízos de uma indústria. Nesse contexto, os autores ensinam como se identificar situações que podem ser representadas por números positivos e negativos.
} 
Os autores anunciam dois aspectos, o primeiro referente a que aluno possa, além de conhecer, aplicar os conceitos que forem ensinados no decorrer do livro; e, o segundo, que seja possível desenvolver interesse pela resolução de situações da própria Matemática, principalmente, o interesse pelos desafios presentes nessas situações. Além disso, consideram que as abstrações não devem estar no início ou no fim dos processos de ensino, mas sim, estar presentes em todos os momentos para a construção do conhecimento matemático.

Os autores indicam a valorização das diversas formas de resolução que podem ser identificadas por meio de problemas, que contemplam aplicações, mobilização de procedimentos e investigação das soluções apresentadas. Nesse caso, se esses processos trazidos pelos autores do livro didático, tiverem ligação com o bloco do saber, há grande oportunidade que se obtenha os resultados almejados: que os estudantes não sejam meros memorizadores de fórmulas, e que as justificativas para as técnicas estejam presentes nos processos de ensino. Para que o aluno tenha condições de trabalhar com sua criatividade e apresentar formas alternativas de resolução é necessário que ele compreenda as propriedades, os procedimentos, os algoritmos, que ele seja participante em seus processos de aprendizagem.

O primeiro contato que os alunos têm com os números inteiros relativos é, geralmente, com situações monetárias, de variação de temperatura e de altitudes, entre outras, em que, como dito anteriormente, busca-se um modelo em que algumas características se aproximam dos conceitos dos inteiros relativos a que se deseja ensinar. Borba (2009, p. 70) afirma que, "pode-se iniciar a partir dos significados, propriedades e representações que seus alunos já conhecem e mediar um aprofundamento do conhecimento em outros aspectos do conceito ainda não bem compreendidos". A respeito dessa abordagem Cid (2003, p. 3), considera que,

\footnotetext{
É uma apresentação dos números inteiros com base em sua similaridade com outros sistemas de objetos que são familiares aos estudantes ou que podem ser mais atraentes para eles. Supõe-se que, com base em sua experiência com o modelo, pode conjecturar ou, pelo menos, justificar, "fazer sentido" de suas regras operacionais e, mais tarde, por analogia, estendê-las ao conjunto de números inteiros.
}

Corroborando com Borba (2009), o autor supracitado levanta a necessidade de formalização dos conceitos introduzidos via modelos concretos: 


\begin{abstract}
Além disso, cabe ressaltar que são poucos os autores que, uma vez introduzida a noção de número inteiro por meio de um ou vários modelos específicos, levantam a necessidade de um processo de formalização, descontextualização da noção inicialmente apreendida. Mesmo alguns não parecem distinguir entre o conhecimento do modelo e o conhecimento da noção matemática e asseguram, por exemplo, que um estudante "aprendeu" a adição e a subtração de números inteiros, simplesmente porque eles desenvolveram uma certa habilidade no gerenciamento de chips de duas cores que são neutralizados entre eles. (CID, 2003, p.8)
\end{abstract}

Em vista de se desenvolver um processo de ensino, preocupado que os alunos não sigam apenas modelos e regras, percebe-se que tanto o domínio por parte dos professores, que irão ensinar os conceitos, quanto para os alunos que estão em processos de aprendizagem, os estudos do bloco do saber são importantes. Não estamos aqui falando, nem discutindo que ambos devem conhecer profundamente, tais justificativas, afinal, ambos têm posições diferentes com relação ao saber e isso é natural. Mas, fazer algo (realizar uma tarefa) sem qualquer conhecimento das razões pelas quais o modo como ela foi resolvida funciona, aproxima-se perigosamente do modelo "resolver atividades mecanicamente" e isso não é o que acreditamos que seja fazer matemática.

O exemplo que escolhemos foi o de comparar dois inteiros relativos. O destaque é a imagem de um termômetro, que será o objeto da realidade usado para a associação de números positivos e negativos às temperaturas acima e abaixo de zero, respectivamente.

Figura 2 - Comparação de dois números: pensando nas temperaturas.

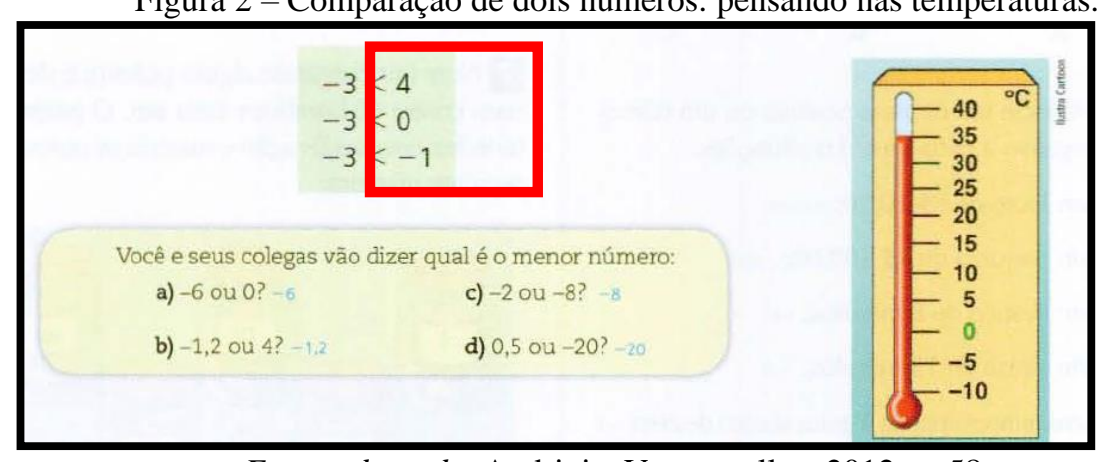

Fonte adaptada: Andrini e Vasconcellos, 2012, p. 58.

Para retratar a temperatura mais baixa em um inverno os autores trazem o seguinte excerto: "Uma temperatura de $-3^{\circ} \mathrm{C}$ é menor do que uma temperatura de $-1{ }^{\circ} \mathrm{C}$, e as duas temperaturas negativas são menores do que a temperatura de $0{ }^{\circ} \mathrm{C}$ em Curitiba e do que a temperatura positiva de $4{ }^{\circ} \mathrm{C}$ em Porto Alegre" (ANDRINI, VASCONCELLOS, 2012, p.58). A partir dessa frase os autores concluem que, '4' e '0' são maiores que '- 3', como destacado em vermelho. A sensação térmica, calor, e o termômetro, possivelmente, dão as justificativas das temperaturas ' +4 ' e ' 0 ' serem as maiores. 
Essa técnica revela que, para comparar dois números inteiros, o procedimento consiste em associar as quantidades dadas às suas representações em um termômetro, em seguida, observar qual é a representação mais alta, para a maior quantidade. Os autores no decorrer desses processos de ensino, vinculam essa técnica à reta numérica, valendo-se da afirmação que "a reta numérica também nos ajuda a comparar números. Entre dois números, qual é o maior? Basta observar qual tem representação mais à direita na reta numérica: esse é o maior" (ANDRINI, VASCONCELLOS, 2012, p. 60).

Sendo assim, para o ensino de uma técnica que permita comparar dois inteiros, os autores partem de justificativas vinculadas a um modelo concreto - termômetros - há em seguida uma passagem dessa técnica para o modelo de reta numérica, que se configura como o momento de institucionalização desse ensino. E, as justificativas para a técnica estão vinculadas a observação do deslocamento das representações no termômetro que se assemelha à ideia que os autores trazem para a reta numérica. Essa sequência de ensino nos permitiu descrever aspectos da transposição didática e das escolhas metodológicas que comporam as Organização Didática desses autores.

\section{Considerações}

Nessa escrita não apontamos os conceitos matemáticos que poderiam compor o bloco do saber do números inteiros relativos, mas sim, tentamos apresentar a importância da mobilização desse bloco para os processos de ensino e aprendizagem. Uma das motivações para a escrita desse artigo foi articular, teoricamente, duas questões: o que a compreensão desse bloco pode nos "oferecer" para os estudos das atividades matemáticas, tanto em relação à sua mobilização em processos de pesquisa quanto em processos de ensino? Qual aporte teórico que o estudo do bloco do saber proporciona às pesquisas?

Em relação ao primeiro questionamento, o bloco do saber oferece aspectos distintos para os processos de ensino e de pesquisa. Em nosso exemplo, foi a mobilização do bloco do saber que nos conduziu a percorrer o caminho em que desenhamos os distanciamentos e aproximações entre o saber apresentado formalmente e o apresentado na proposta de ensino de um livro didático. E, para os processos de ensino, mostramos que esse bloco pode auxiliar o professor em seus processos de planejamento de suas aulas. Por exemplo, o significado de relação dos inteiros relativos pode ser um obstáculo ao ensino, quando o ensino tem foco apenas no significado de medida (BORBA, 2009). Outro exemplo seria 
as distintas interpretações do sinal de menos. Ele pode representar a operação de subtração, o simétrico de um inteiro e, ainda representar que uma quantidade é negativa. Como dito anteriormente, não queremos afirmar que o professor deva ter um aprofundamento muito extenso do bloco do saber, mas a compreensão de aspectos desse bloco pode auxiliá-lo em seu trabalho de planejar novas formas de ensino para as dificuldades de aprendizagem de seus alunos.

A segunda questão, ainda necessita de alguns aprofundamentos teóricos, mas, segundo (BOSCH, GASCÓN, 2010) como toda atividade humana, particularmente as matemáticas, necessitam de um discurso racional, identificamos uma das características dessa ferramenta da TAD, ou seja, esse discurso tem característica de descrever, justificar, interpretar e desenvolver as praxeologias, fornecendo aspectos que permitam gerenciar toda a atividade matemática. Permitindo assim, que essa praxeologia sobreviva em determinada instituição. Se esse bloco não for explicitado de maneira que possibilite que a sua função possa ser exercida, essa praxeologia pode deixar de existir, sendo substituída por outra.

\footnotetext{
Este é o processo usual, relativamente rápido, seguido pela maioria das inovações didáticas espontâneas implementadas pelas sucessivas reformas do ensino de matemática. Ao não conseguir difundir discursos tecnológicoteórico suficientemente "resistentes" e funcionais para manter em vida, desenvolver e dar sentido as distintas práxis didáticas que impulsiona cada reforma, estás tendem a funcionar com muita rigidez, perdendo efetividade e acabam sendo abandonadas (BOSCH, GASCÓN, 2010, p. 58).
}

Dessa forma, o bloco tecnológico-teórico permite ao pesquisador investigar vários aspectos da ecologia do saber em jogo, pois como, Bosch e Gascón (2010) afirmam, se esse discurso não for "competente" a praxeologia que ele justifica não terá condições ecológicas de sobrevivência.

Para o caso dos números inteiros relativos, alguns aspectos ecológicos ${ }^{11}$ foram identificados na dissertação, mas alguns outros devem ser investigados, por exemplo, de que forma o bloco tecnológico-teórico que identificamos no livro didático, baseado em criações didáticas, descreveu, justificou, interpretou e desenvolveu a praxeologia dos inteiros de forma que não fosse substituída por outra organização didática gerada pelas reformas educacionais atuais? Esse questionamento pode ser acrescido de outra indagação: quais foram as circunstâncias que permitiram que esse modelo de ensino, que

\footnotetext{
${ }^{11}$ Para mais informações, ver Gonçalves (2016).
} 
foi duramente questionado e conviveu com vários outros desenvolvidos com intuito de substituí-lo, sobrevivesse nas instituições de ensino atuais? As respostas para esses e outros questionamentos pretendemos responder em nosso processo de doutoramento.

\section{Referências}

ANDRINI, Álvaro. VASCONCELLOS, Maria José. Praticando Matemática, 7. 3. ed. renovada. São Paulo: Editora do Brasil, 2012.

BITTAR, Marilena. A Teoria Antropológica do Didático como ferramenta metodológica para análise de livros didáticos. Zetetiké, Campinas/SP, v. 25, ISSN 2176-1744, 2017.

BORBA, Rute; GUIMARÃES, Gilda. A pesquisa em educação matemática: repercussões na sala de aula. São Paulo: Cortez, 2009.

BOSCH, Marianna. GASCÓN, Josep. Fundamentación antropológica de las organizaciones didácticas: de los talleres de prácticas matemáticas a los recorridos de estudio e investigación. In : A. Bronner, M. Larguier, M. Artaud, M. Bosch, Y. Chevallard, G. Cirade \& C. Ladage (Eds.), Diffuser les mathématiques (et les autres savoirs) comme outils de connaissance et d'action (pp. 55-91). Montpellier, França: IUFM, 2010.

CHEVALLARD, Yves. Conceitos Fundamentais da Didática: As perspectivas trazidas por uma Abordagem Antropológica. In: Jean Brun (Ed.). Didáctica das Matemáticas. Lisboa: Instituto Piaget, p. 114 - 154, 1996.

Analyse des pratiques enseignantes et didactique des mathematiques: L'approche antropologique. Publicado em: Recherches en Didactique des Mathématiques, v. 19, n. 2, p. 221 - 266, 1999.

CID, E. La investigación didáctica sobre los números negativos: estado de la cuestión. Pre-publicaciones del Seminario Matemático" García de Galdeano", n. 25, p. 1 - 40, 2003.

FREITAS, Maxlei Vinícius Cândido de. Um estudo sobre volume de sólidos geométricos em quatro coleções de livros didáticos do ensino médio. Dissertação de mestrado, Universidade Federal do Mato Grosso do Sul, Campo Grande, 2015.

GONÇALVES, Kleber Ramos. A teoria antropológica do didático como ferramenta para o estudo de transposições didáticas: o caso das operações de adição e subtração dos números inteiros no $7^{\circ}$ ano do ensino fundamental. Dissertação de mestrado, Universidade Federal do Mato Grosso do Sul, Campo Grande, 2016. 